\title{
A. Caudate
}

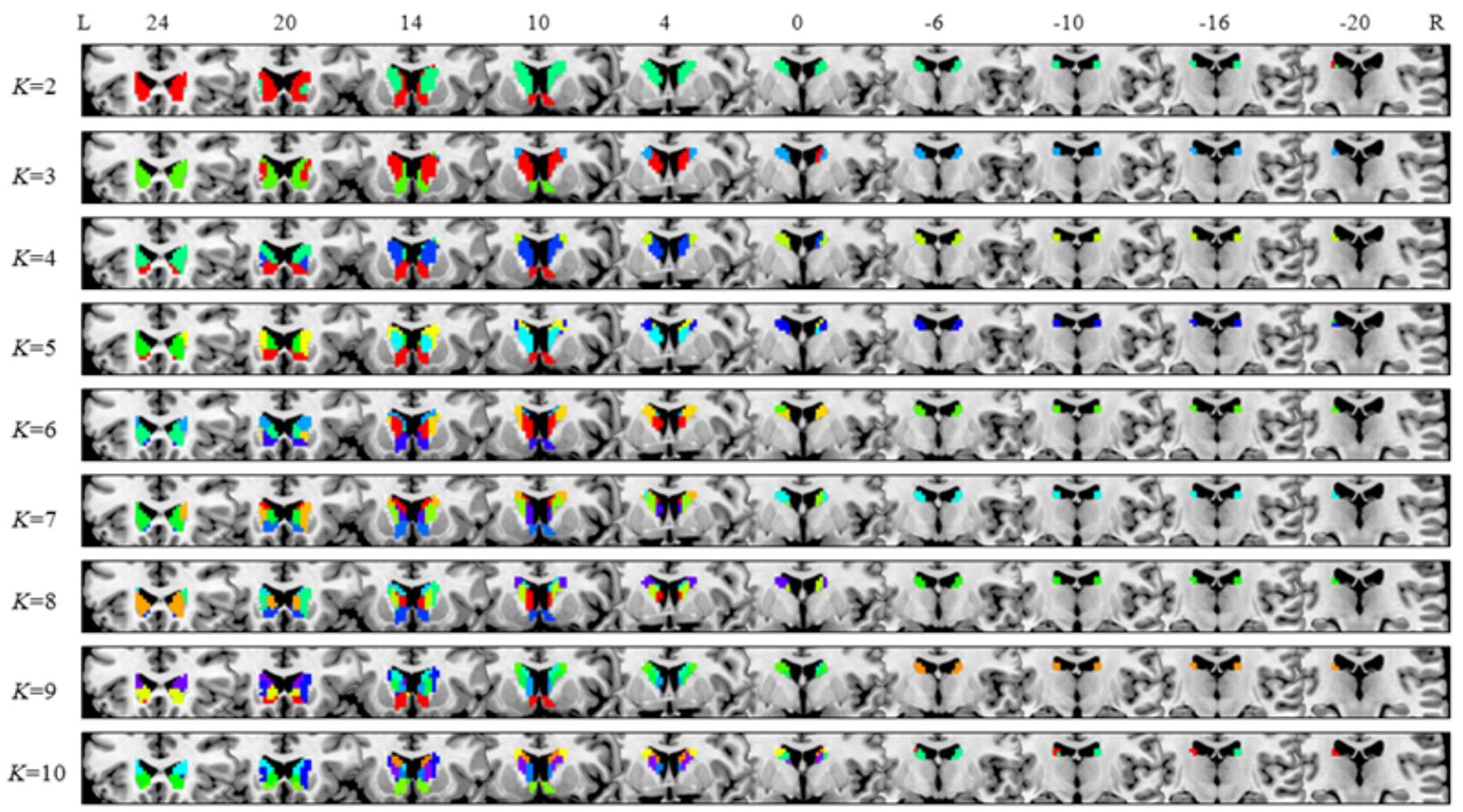

B. Putamen

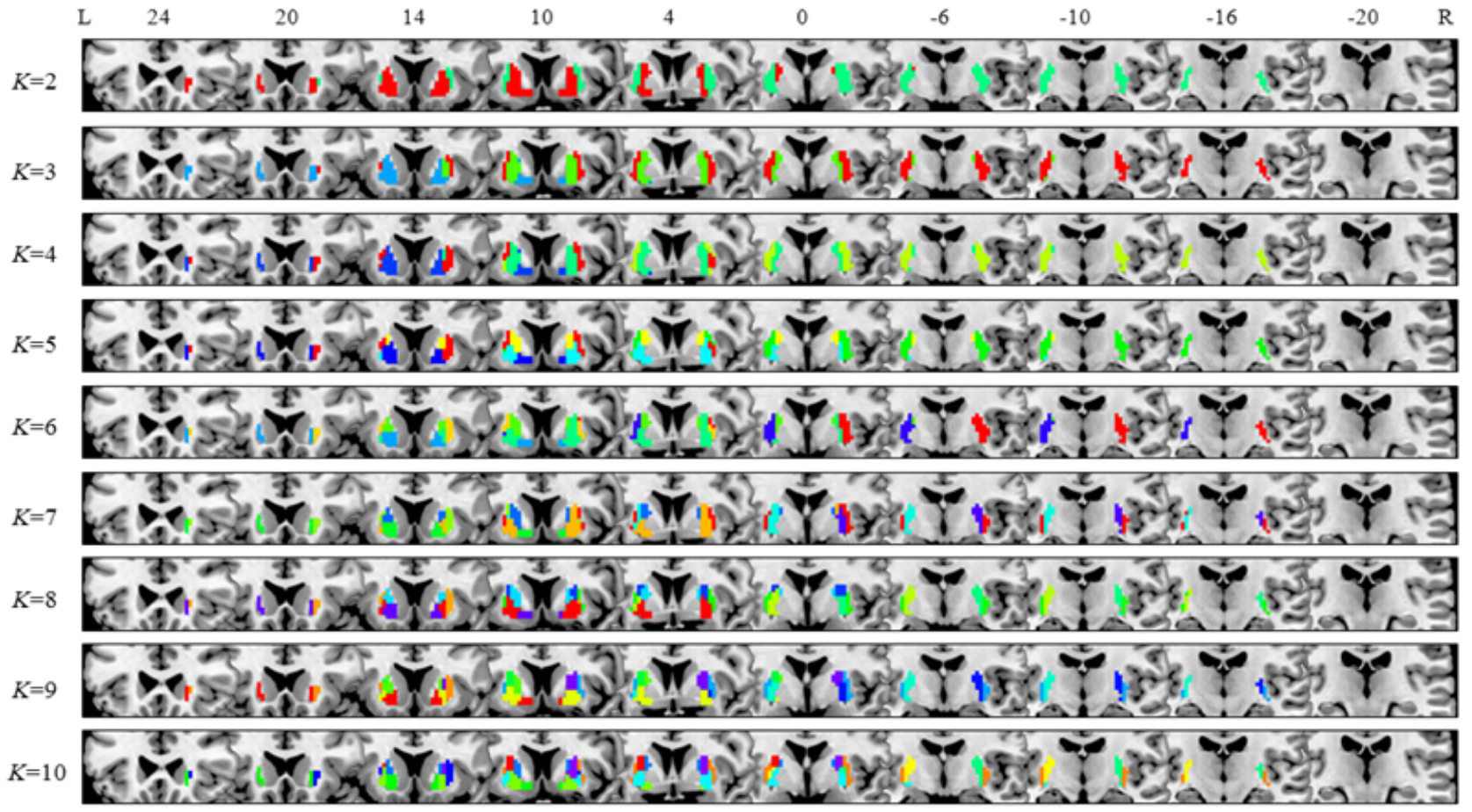

Figure S1. Coronal view showing functional connectivity-based parcellation of the caudate (A) and putamen (B) for cluster solutions with different $K(2-10)$. With an increase in $K$, the functional subdivisions of the caudate and putamen were much more detailed and segmented along the ventro-dorsal, anterior-posterior, or medio-lateral axis. 